\title{
A Novel Itraconazole Pulse Therapy Schedule in the Treatment of Tinea Capitis in Children
}

\author{
Ya Bin Zhou (1D* \\ Yuan Yuan Xiao* \\ Jin Jing Chao \\ Lin Ma
}

Department of Dermatology, Beijing Children's Hospital, Capital Medical

University, National Center for

Children's Health, Beijing, I00045,

People's Republic of China

*These authors contributed equally to this work
Correspondence: Yuan Yuan Xiao Department of Dermatology, Beijing Children's Hospital, Capital Medical University, National Center for Children's Health, Beijing, I00045, People's Republic of China

Tel +861059616884

$\mathrm{Fax}+861059718700$

Emailxyy8I924@I26.com

\begin{abstract}
Tinea capitis is a common dermatophytosis predominantly occurring in children, which needs oral antifungal drug therapy. Itraconazole pulse therapy has been widely applicated in the treatment of adult onychomycosis. However, only a few studies are available for the treatment of pediatric tinea capitis with itraconazole pulse therapy. The therapy schedules vary with respect to dose and intermission. Here, we report four cases of tinea capitis that were treated with a novel high-dose itraconazole pulse therapy $(6-10 \mathrm{mg} /$ $\mathrm{kg} / \mathrm{d}$ with 3 weeks off between consecutive pulses). After 2-3 pulses therapy, all the patients were cured and no adverse reactions were observed. We demonstrate the efficacy and safety of this novel itraconazole pulse therapy schedule. It may be a promising therapy in the treatment of tinea capitis in children.
\end{abstract}

Keywords: tinea capitis, itraconazole pulse therapy, children, Microsporum canis, Nannizzia gypsea

\section{Introduction}

Tinea capitis is a common dermatophytosis occurring on the scalp and hair follicles, mainly involves prepubertal children. ${ }^{1}$ Griseofulvin, terbinafine, itraconazole and fluconazole are the most popular oral antifungal agents for the treatment of tinea capitis. ${ }^{2}$ Itraconazole pulse therapy with a higher dose has been widely applicated in the treatment of adult onychomycosis. It is more safety and cheaper than continuous therapy. ${ }^{3}$ Nonetheless, only a few researches with various schedules have depicted itraconazole pulse therapy in the treatment of tinea capitis in children. ${ }^{4-9}$ Gupta et al first depicted itraconazole pulse therapy for tinea capitis in children with 2 weeks off between consecutive pulses. ${ }^{4}$ However, they changed the schedule with 2 -week period between the first and second pulses and 3-week period between the second and third pulses in consequent studies. ${ }^{5,6}$ Other studies also conducted schedules with 3 weeks off between consecutive pulses. ${ }^{8,9}$ Increased dose of itraconazole results in a significant increase in nail drug levels. ${ }^{10}$ Therefore, the recommended dose of itraconazole pulse therapy $(400 \mathrm{mg} / \mathrm{d})$ is doubled compared with continuous therapy in adult onychomycosis. We considered that dose of itraconazole pulse therapy for tinea capitis in children should also be increased. However, the doses of pulse therapy in the abovementioned studies for tinea capitis in children were all identical to those of continuous therapy. Here, we described a novel itraconazole (Sporanox, Janssen Pharmaceutica Inc.) pulse therapy schedule with an increased dose in the treatment of tinea capitis in children. 


\section{Patients and Methods}

Four patients with tinea capitis were treated with itraconazole pulse therapy (6-10 mg/kg/d with 3 weeks off between consecutive pulses). All the patients except patient 1 were given oral itraconazole capsules. Patient 1 was given oral itraconazole solution instead because she could not swallow the capsules. Fungal culture of lesional hairs yielded Microsporum canis (patient 1, 3 and 4) and Nannizzia gypsea (patient 2). Besides oral itraconazole, they were all treated with topical terbinafine hydrochloride cream twice daily. The number of itraconazole pulses was determined by mycologic examinations and clinical symptoms of each patient. Itraconazole pulse therapy was discontinued until clinical and mycologic cure. Laboratory of hepatic function was conducted monthly during the treatment of itraconazole. To control inflammation, patient 4 was also given oral prednisone $45 \mathrm{mg} / \mathrm{d}$ for two weeks. Prednisone was tapered to withdraw in 2 weeks.

\section{Results}

As can be seen from Table 1, all the patients were cured after 2-3 pulse of itraconazole therapy. During the treatment of oral itraconazole, the patients were all well tolerated without any hepatic function injury and clinical adverse reactions. No relapse was reported on follow up. The images of the four patients before and after itraconazole pulse therapy were presented in -Figure 4 .

\section{Discussion}

Gupta et al found that 1-3 pulses of itraconazole therapy could be enough to cure tinea capitis in children caused by Trichophyton spp. ${ }^{4-7}$ However, more pulses should be needed for tinea capitis caused by $M$. canis. A previous study showed most $M$. canis tinea capitis needed 2-4 pulses of itraconazole therapy and 4 patients were cured with up to 7 pulses. ${ }^{8}$ In addition, a previous study showed only $37.0 \%$ of patients with Microsporum ferrugineum tinea capitis were cured after 4 pulses of itraconazole therapy. ${ }^{9}$ In our study, only 2-3 pulses of itraconazole therapy were needed to cure
M. canis and $N$. gypsea tinea capitis. We considered that the increased dose of itraconazole might improve the clinical efficacy. However, this improvement should be evaluated by more patients in the future.

Tinea capitis usually requires oral antifungal drugs because topical antifungal drugs are unable to penetrate the hair shaft sufficiently to clear the infection. Furthermore, topical antifungal drugs alone may contribute to the creation of carriers whose symptoms and clinical signs are minimal but who are still mycologically positive and presumed to be capable of transmitting infection. ${ }^{11}$ However, topical antifungal agents should still be used in an effort to reduce the infectiousness and dissemination of spores, shorten the time systemic antifungal agents and to treat asymptomatic carriers. ${ }^{12}$ Therefore, topical terbinafine was also used in our patients.

Itraconazole has comparable efficacy with griseofulvin or terbinafine and activity against both Microsporum and Trichophyton. ${ }^{13}$ The highly lipophilic and keratophilic nature of itraconazole has enabled it to be used as pulse therapy. ${ }^{4}$ A previous study investigated the population pharmacokinetics (PK) and pharmacodynamics (PD) of itraconazole for adult patients with talaromycosis. ${ }^{14}$ Itraconazole pharmacokinetic variability was considerable, with areas under the concentration-time curve over 24 $\mathrm{h}$ (AUC24) of $3.34 \pm 4.31 \mathrm{mg} \bullet \mathrm{h} /$ liter. ${ }^{14}$ Itraconazole minimum concentration (Cmin) was $0.11 \pm 0.16 \mathrm{mg} /$ liter and there were no associations between itraconazole $\mathrm{Cmin} /$ MIC and time to sterilization of the bloodstream, time to death, or early fungicidal activity. ${ }^{14}$ However, the PK/PD characteristics of itraconazole in children is still uncertain.

For adult patients, the dose of itraconazole pulse therapy (400 mg/d) is twice as high as continuous therapy. ${ }^{3}$ The recommended dose of itraconazole continuous therapy for pediatric patients is $3-5 \mathrm{mg} / \mathrm{kg} / \mathrm{d}{ }^{8}$ Therefore, we consider that a doubled dose of $6-10 \mathrm{mg} / \mathrm{kg} / \mathrm{d}$ is suitable for itraconazole pulse therapy. For very young patients who are unable to swallow the capsule, oral solution is an appealing option.

Table I Characteristics of Patients with Tinea Capitis

\begin{tabular}{|l|l|l|l|l|l|l|l|l|}
\hline $\begin{array}{l}\text { Patient } \\
\text { No. }\end{array}$ & $\begin{array}{l}\text { Age } \\
\text { (Years) }\end{array}$ & Sex & $\begin{array}{l}\text { Weight } \\
(\mathbf{k g})\end{array}$ & $\begin{array}{l}\text { Dose of Itraconazole } \\
(\mathbf{m g} / \mathbf{d})\end{array}$ & $\begin{array}{l}\text { No. of } \\
\text { Pulse }\end{array}$ & Organism & $\begin{array}{l}\text { Adverse } \\
\text { Reaction }\end{array}$ & Follow Up \\
\hline $\mathrm{I}$ & 2 & $\mathrm{M}^{\mathrm{a}}$ & 12 & 120 & 2 & M. canis & None & No relapse \\
2 & 3 & $\mathrm{~F}^{\mathrm{b}}$ & 13.5 & 100 & 2 & N. gypsea & None & No relapse \\
3 & 5 & $\mathrm{M}$ & 18.5 & 150 & 3 & M. canis & None & No relapse \\
4 & 8 & $\mathrm{M}$ & 23 & 200 & 3 & M. canis & None & No relapse \\
\hline
\end{tabular}

Abbreviations: ${ }^{\mathrm{a}}$, female; ${ }^{\mathrm{b}} \mathrm{M}$, male. 


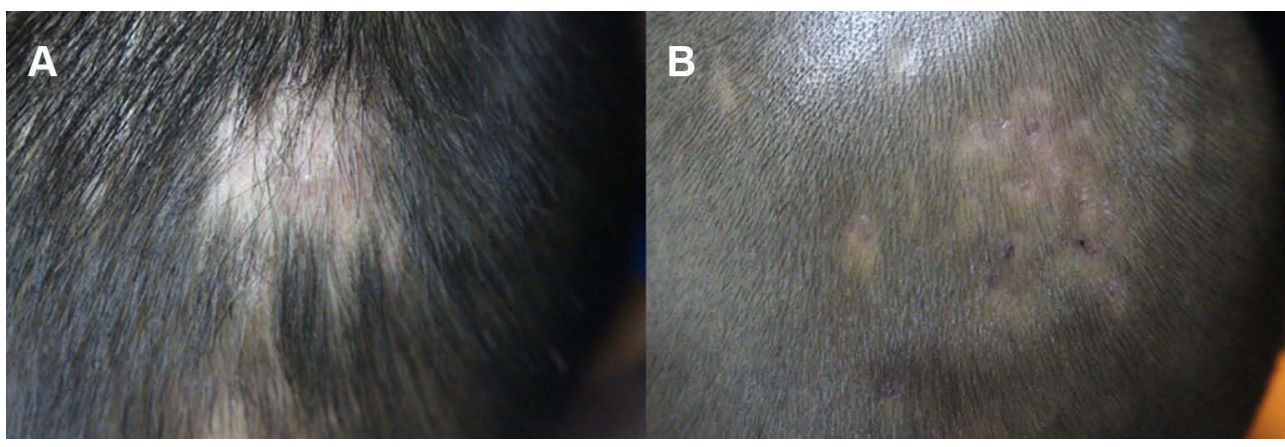

Figure I (A) Clinical manifestation of patient I. (B) Complete remission after treatment of patient I.

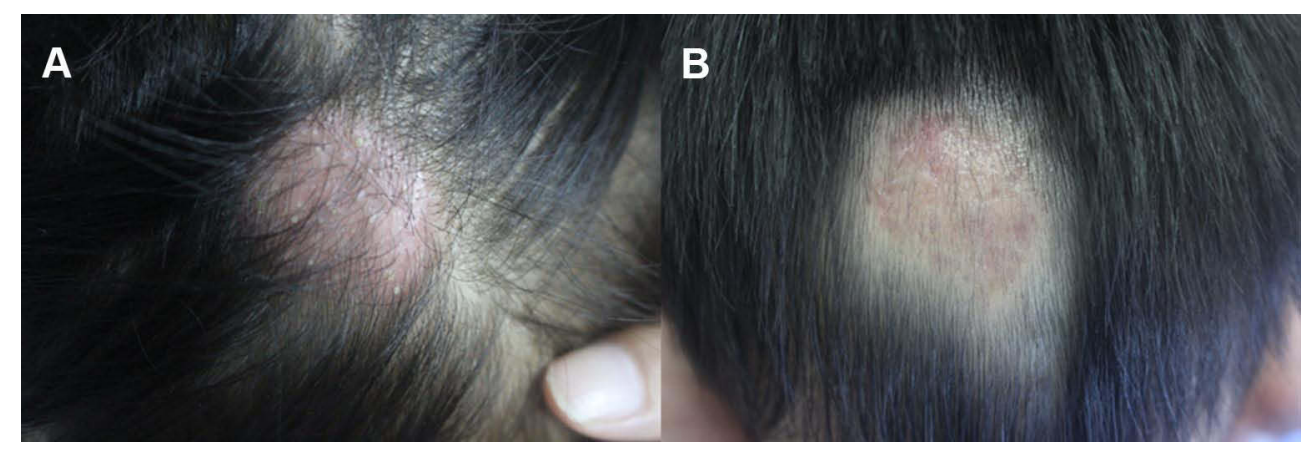

Figure 2 (A) Clinical manifestation of patient 2. (B) Complete remission after treatment of patient 2.
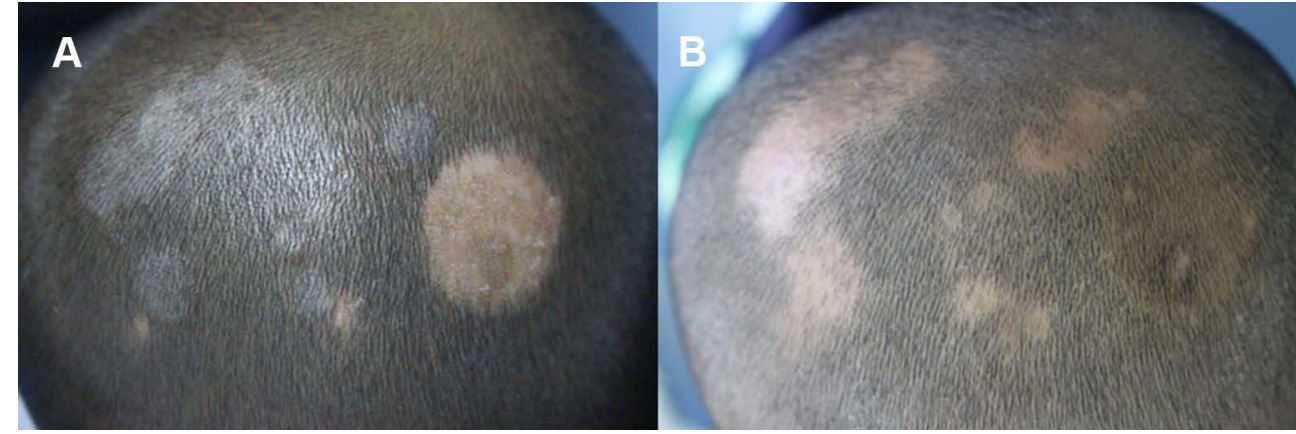

Figure 3 (A) Clinical manifestation of patient 3. (B) Complete remission after treatment of patient 3.

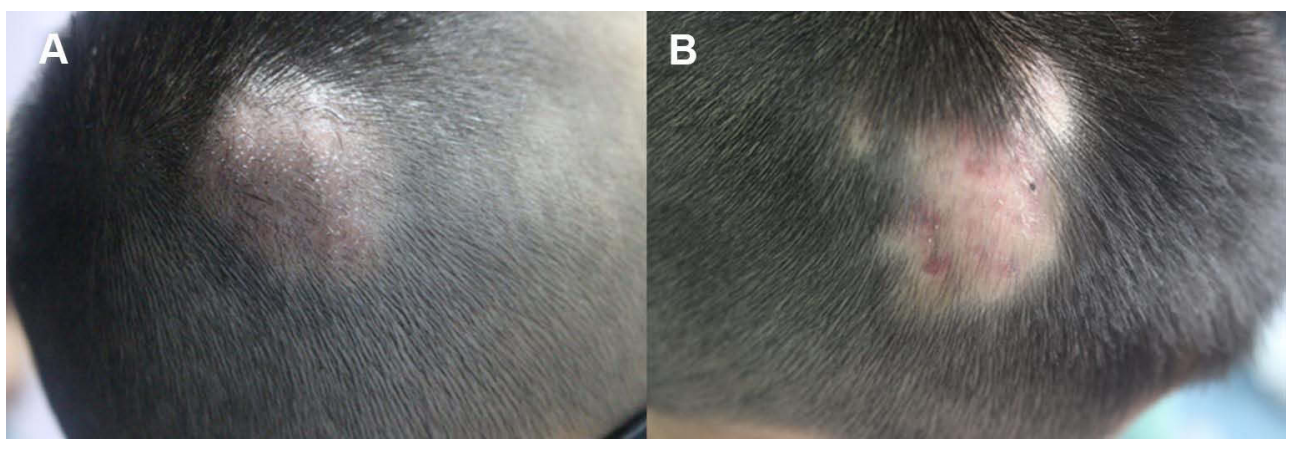

Figure 4 (A) Clinical manifestation of patient 4. (B) Complete remission after treatment of patient 4. 
A previous study demonstrated the efficacy and safety of itraconazole oral solution pulse therapy $(3 \mathrm{mg} / \mathrm{kg} / \mathrm{d}){ }^{7}$ It seems that an increased dose of itraconazole oral solution pulse therapy $(10 \mathrm{mg} / \mathrm{kg} / \mathrm{d})$ is also effective and safe.

Itraconazole pulse therapy for onychomycosis in children has also been used. A previous study found that 16 of the 17 children with onychomycosis responded fully to itraconazole pulse therapy and no patients experienced any clinical adverse reactions. ${ }^{15}$ Hepatic function test is recommended for itraconazole continuous therapy and periodic monitoring (4-6 weeks) is suggested in adults. ${ }^{3}$ However, hepatic function test is not required for itraconazole pulse therapy in adults unless there is a history of hepatic disease, other hepatotoxic drugs, or abnormal liver function at baseline, or if signs or symptoms develop at any time to suggest liver dysfunction. ${ }^{3}$ Previous studies did not perform regular hepatic function test for children treated with itraconazole pulse therapy. ${ }^{4-9}$ Although no hepatic function injury was detected in our patients, we considered that it would be better to monitor hepatic function test during itraconazole pulse therapy in children.

\section{Conclusion}

In conclusion, this small case series demonstrates the efficacy and safety of an itraconazole pulse therapy schedule with a high dose $(6-10 \mathrm{mg} / \mathrm{kg} / \mathrm{d}$ with 3 weeks off between consecutive pulses) in the treatment of tinea capitis in children. Itraconazole pulse therapy was discontinued until clinical and mycologic cure (2-3 pulses in our study). Pulse therapy relates to a high degree of compliance for children, which makes it a prospective therapeutic schedule. The efficacy and safety of itraconazole pulse therapy with a high dose should be evaluated in a large cohort of children and compared with traditional continuous therapy.

\section{Informed Consent Statement}

The patients' parents had given written informed consent for the publication of the case details and all accompanying images.

\section{Funding}

This work was supported by the Capital Medical Development Research Fund No. 2020-2-4078 and
Special Fund of the Pediatric Medical Coordinated Development Center of Beijing Hospitals Authority No. XTZD20180502.

\section{Disclosure}

The authors declare no conflicts of interest.

\section{References}

1. Gupta AK, Mays RR, Versteeg SG, et al. Tinea capitis in children: a systematic review of management. $J$ Eur Acad Dermatol Venereol. 2018;32(12):2264-2274. doi:10.1111/jdv.15088

2. Zampella JG, Kwatra SG, Blanck J, Cohen B. Tinea in tots: cases and literature review of oral antifungal treatment of tinea capitis in children under 2 years of age. $J$ Pediatr. 2017;183:12-8.e3. doi:10.1016/j.jpeds.2016.12.042

3. Eisman S, Sinclair R. Fungal nail infection: diagnosis and management. BMJ. 2014;348:g1800. doi:10.1136/bmj.g1800

4. Gupta AK, Alexis ME, Raboobee N, et al. Itraconazole pulse therapy is effective in the treatment of tinea capitis in children: an open multicentre study. $B r \quad J$ Dermatol. 1997;137(2):251-254. doi:10.1046/j.1365-2133.1997.18141912.x

5. Gupta AK, Adam P, De Doncker P. Itraconazole pulse therapy for tinea capitis: a novel treatment schedule. Pediatr Dermatol. 1998;15 (3):225-228. doi:10.1046/j.1525-1470.1998.1998015225.x

6. Gupta AK, Hofstader SLR, Summerbell RC, et al. Treatment of tinea capitis with itraconazole capsule pulse therapy. $\mathrm{J} \mathrm{Am} \mathrm{Acad} \mathrm{Dermatol.}$ 1998;39(2):216-219. doi:10.1016/s0190-9622(98)70078-7

7. Gupta AK, Adam P, Soloman R, Aly R. Itraconazole oral solution for the treatment of tinea capitis using the pulse regimen. Cutis. 1999;64 (3):192-194.

8. Koumantaki-Mathioudaki E, Devliotou-Panagiotidou D, Rallis E, et al. Is itraconazole the treatment of choice in Microsporum canis tinea capitis? Drugs Exp Clin Res. 2005;31:11-15.

9. Wisuthsarewong W, Chaiprasert A. Treatment of tinea capitis caused by Microsporum ferrugineum with itraconazole. J Med Assoc Thai. 2005;88(Suppl 8):S72-S79.

10. Debruyne D, Coquerel A. Pharmacokinetics of antifungal agents in onychomycoses. Clin Pharmacokinet. 2001;40(6):441-472. doi: 10.2165/00003088-200140060-00005

11. Fuller LC, Child FJ, Midgley G, Higgins EM. Diagnosis and management of scalp ringworm. BMJ. 2003;326(7388):539-541. doi:10.1136/bmj.326.7388.539

12. Mayser P, Nenoff P, Reinel D, et al. S1 guidelines: tinea capitis. $J$ Dtsch Dermatol Ges. 2020;18(2):161-179. doi:10.1111/ ddg. 14026

13. Fuller LC, Barton RC, Mohd Mustapa MF, Proudfoot LE, Punjabi SP, Higgins EM. British Association of Dermatologists' guidelines for the management of tinea capitis 2014. Br J Dermatol. 2014;171 (3):454-463. doi:10.1111/bjd.13196

14. Stott KE, Le T, Nguyen T, et al. Population pharmacokinetics and pharmacodynamics of itraconazole for disseminated infection caused by Talaromyces marneffei. Antimicrob Agents Chemother. 2021;65 (11):e0063621. doi:10.1128/AAC.00636-21

15. Huang PH, Paller AS. Itraconazole pulse therapy for dermatophyte onychomycosis in children. Arch Pediatr Adolesc Med. 2000;154 (6):614-618. doi:10.1001/archpedi.154.6.614 


\section{Publish your work in this journal}

Clinical, Cosmetic and Investigational Dermatology is an international, peer-reviewed, open access, online journal that focuses on the latest clinical and experimental research in all aspects of skin disease and cosmetic interventions. This journal is indexed on CAS.

The manuscript management system is completely online and includes a very quick and fair peer-review system, which is all easy to use. Visit http://www.dovepress.com/testimonials.php to read real quotes from published authors.

Submit your manuscript here: https://www.dovepress.com/clinical-cosmetic-and-investigational-dermatology-journal 